\title{
THE EFFECT OF MOTIVATIONAL MUSIC ON AEROBIC AND ANAEROBIC PERFORMANCE AMONG OVERWEIGHT CHILDREN
}

\author{
Alon Eliakim ${ }^{1}$, Michal Eliakim ${ }^{1}$, Michal Pantanowitz $^{1,2}$, \\ Yoav MeCKeL ${ }^{2}$, Dan NemeT ${ }^{1}$ \\ ${ }^{1}$ Child Health \& Sport Center, Pediatric Department, Meir Medical Center, Sackler \\ School of Medicine, Tel-Aviv University, Israel \\ ${ }^{2}$ Zinman College of Physical Education, Wingate Institute, Netanya, Israel
}

\begin{abstract}
The present study examined whether background music improves aerobic and anaerobic performance in overweight children. Eleven participants (14.6 \pm 1.5 yrs, BMI\%: 94.3 \pm 6.5 ) performed aerobic (20m Shuttle Run) and anaerobic (repeated sprint test - RST) field tests. Ten participants (12.0 $\pm 2.1 \mathrm{yrs}$, BMI\%:97.4 \pm 1.6 ) performed aerobic (treadmill running) and anaerobic (Wingate Anaerobic Test - WAnT) laboratory tests. Treadmill running time was significantly longer with, compared to without, music ( $11.9 \pm 1.5$ versus $10.6 \pm 2.2 \mathrm{~min}$, respectively; $\mathrm{p}<0.007)$. There was no significant difference in the $20 \mathrm{~m}$ shuttle run distance with or without music. Total sprint time was significantly faster during RST with, compared to without, music $(47.7 \pm 4.7$ versus $48.5 \pm 5.5 \mathrm{~s}$, respectively; $\mathrm{p}<0.04)$, with no significant difference in ideal sprint time and performance decrement. There was no significant difference in peak and mean anaerobic power and fatigue index during the WAnT with and without music. Motivational music may be used to improve aerobic and anaerobic performance among overweight children.
\end{abstract}

Keywords: music, aerobic performance, anaerobic performance, overweight children

\section{INTRODUCTION}

The mechanisms responsible for the increasing prevalence of childhood obesity are not entirely understood, yet life-style changes associated with increased caloric intake and decreased energy expenditure probably play 
a major role, especially in genetically predisposed population $[7,11,18]$. This indicates that preventive health education and therapeutic programs for childhood obesity require a multi-disciplinary approach, that includes life-style/behavioral modification, nutritional education and changes in physical activity patterns $[16,24,31]$. It is recommended that children and adolescent should perform at least $60 \mathrm{~min}$ of cumulative daily moderate to vigorous physical activity [28]. However, obese children often fail to follow these recommendations, and cannot carry on physical activity for long time periods [10]. Obese children's inability to follow the physical activity guidelines is partially explained by difficulties to overcome unpleasant body symptoms and sensations (e.g. chest pain/pressure, pounding heart, nausea and vomiting, dizziness, skeletal/muscle pain etc.) [2]. Moreover, the preferred exercise training regimen, and the relative contribution of aerobic, anaerobic or resistance exercise for the "optimal" weight management training intervention for obese children, is unknown.

Music is used frequently to increase motivation and improve aerobic and anaerobic performance [20]. However, while exercise participants report favorable subjective effects of music during exercise (e.g. mood, motivation etc.) [4], research has not always supported this notion $[6,12,30]$. Research on the effects of music on exercise performance yielded conflicting results $[3,8,25]$, and it was suggested that the timing and type of music, the type of exercise and the individual's fitness level and personality, may all affect performance response to music.

Several mechanisms may explain the beneficial effect of music on performance. These include the natural reaction and synchronization with the music rhythm and tempo. In addition, listening to music may distract performers from the simultaneous exercise-associated sensation of fatigue (The parallel processing model) [26]. Other mechanisms include increased positive and reduced negative moods, and increased likelihood of achieving flow state $[19,30]$. Consistent with this, De Bourdeaudhuij et al. [10] demonstrated that treadmill running time was significantly longer among obese children and adolescents when music was used as a distracter. Interestingly, the distraction effect was greater at the beginning compared to the end of a weight management intervention.

Therefore, the aim of the present study was to examine the effect of motivational music on different modalities of aerobic and anaerobic performance in overweight children at the initial stages of a combined nutritionalbehavioral-physical activity intervention. We hypothesized that listening to music will improve both aerobic and anaerobic performance. 


\section{MATERIALS AND METHODS}

\section{Participants}

Twenty-one male overweight children volunteered to participate in the study. All the overweight children participated in a weight reduction program in the Child Health and Sport Center at the Pediatric Department of Meir Medical Center, Tel-Aviv University. Body Mass Index (BMI) percentile was assessed in all children as an indication of adiposity, and overweight was defined as BMI $>85 \%$. The study was approved by the Institution's ethics committee. The testing procedure was explained to the children and to their parents, and a written informed consent was obtained from both.

\section{Measurements}

Eleven participants $(14.6 \pm 1.5 \mathrm{yrs}, 73.9 \pm 14.8 \mathrm{~kg}, 161.8 \pm 10.1 \mathrm{~cm}$, BMI: $\left.28.0 \pm 3.9 \mathrm{~kg} / \mathrm{m}^{2}, \mathrm{BMI} \%: 94.3 \pm 6.5\right)$ performed field tests for the evaluation of aerobic $(20 \mathrm{~m}$ Shuttle Run), and anaerobic capacity $(12 \times 20 \mathrm{~m}$ repeated sprint test - RST). Ten participants $(12.0 \pm 2.1 \mathrm{yrs}, 63.5 \pm 21.0 \mathrm{~kg}, 153.4 \pm 12.1 \mathrm{~cm}$, BMI: $\left.27.0 \pm 5.3 \mathrm{~kg} / \mathrm{m}^{2}, \mathrm{BMI} \%: 97.4 \pm 1.6\right)$ performed laboratory tests for the evaluation of aerobic (treadmill running), and anaerobic capacity (the Wingate Anaerobic Test - WAnT). The rational for the test's selection was that it may allow us to evaluate the effect of music on both continuous and intermittent activity and in both field and laboratory setting. All tests, with and without motivational music, were separated by 3-5 days from each other, and were performed at random order.

Subjects were asked not to eat and/or drink (except for water) three hours prior to each test. Subjects were also asked to refrain from intensive exercise sessions the day before testing. In order to prevent undesirable effects and/or feelings, each test was performed individually without the presence of other children in the near area. Before each test, children participated in a special habituation session which included the exercise pattern at the intensity level that was required for the upcoming tests. After the habituation session before each test, a warm-up (5 min jogging, 5 min stretching and 3-5 $20 \mathrm{~m}$ running repetitions at increasing speed) was performed by each participant.

\section{Aerobic Power Test}

\section{Treadmill running}

Aerobic capacity was assessed using a progressive treadmill exercise test to determine exercise endurance. After the warm-up all subjects were 
familiarized with the treadmill for five minutes. Exercise started at a speed of $3.5 \mathrm{~km} /$ hour, and an incline of $10^{\circ}$. The exercise intensity was enhanced every two minutes by increasing the elevation of the treadmill by $2.5^{\circ}$ (up to an incline of $22.5^{\circ}$ ). Then the treadmill speed was increased by $1 \mathrm{~km} /$ hour every two minutes [13]. All subjects were encouraged throughout the test by the staff and exercised to the limit of their tolerance.

\section{Twenty-Meter Shuttle Run Test}

The $20 \mathrm{~m}$ shuttle run test is a field test that has been shown to be a reliable and valid indicator [27] of aerobic power in various populations including children older than 8 years old [23]. The test consists of shuttle running at increasing speeds between two markers placed $20 \mathrm{~m}$ apart. A portable compact disc (Sony CFD-V7) dictated the pace of the test by emitting tones at appropriate intervals. The children were required to be at one of the ends of the $20 \mathrm{~m}$ course at the signal. A starting speed of $8.5 \mathrm{~km} / \mathrm{h}$ was maintained for one minute, and thereafter the speed was increased every minute by $0.5 \mathrm{~km} / \mathrm{h}$. The test was terminated when the child withdrew voluntarily from exercise or failed to arrive within $3 \mathrm{~m}$ of the end line on two consecutive tones. The aerobic fitness of each participant was calculated as the total distance achieved during the test.

\section{Anaerobic Power Test}

\section{Wingate Anaerobic Test - WAnT}

Anaerobic performance was evaluated using the Wingate Anaerobic test [1]. Anaerobic work responses were obtained using a Monark 834k cycle ergometer (Monark, Stockholm). Seat height was adjusted to each participant's satisfaction and clips with straps were used to prevent the feet from slipping off the pedals. Each participant cycled for 30 seconds against constant resistance. Resistance was set to $0.06 \mathrm{~kg}$ per each subject's $\mathrm{kg}$ body weight. Participants were instructed to pedal as fast as possible throughout the $30 \mathrm{~s}$ of the test period and were verbally encouraged throughout the test.

In each test the maximal power output, mean power output, minimal power output and the fatigue index were measured. All power outputs measurements are based on five seconds averages that were calculated by the Wingate Anaerobic Test computer software and reported in watts $/ \mathrm{kg}$. Maximal power output (peak power) was calculated from the highest five-seconds work output. Mean power output, which reflects the anaerobic capacity, was calculated as the mean power output throughout the 30 seconds of the test. 
Minimal power output was calculated as the lowest five-seconds work output. Fatigue index was calculated as the percentage of power output drop throughout the test from the maximal power output [1].

\section{Repeated Sprint Test - RST}

The RST included a series of short maximal runs with short rest periods between runs. The protocol consisted of $12 \times 20 \mathrm{~m}$ runs starting every $20 \mathrm{~s}$. A $20 \mathrm{~m}$ all-out sprint was performed at the end of the warm-up by each participant. The time for the $20 \mathrm{~m}$ sprint was used as the criterion score for the subsequent RST. Participants had rested for 5 min between the criterion sprint and the RST. In the first sprint of the RST, participants were required to achieve at least $95 \%$ of their criterion score. This requirement was achieved by all participants.

A photoelectric cell timing system (Alge-Timing Electronic, Vienna, Austria) linked to a digital chronoscope was used to record each sprint and rest interval time with an accuracy of $0.001 \mathrm{~s}$. During the recovery period between sprints, participants tapered down from the sprint they had just completed and walked back to the next starting point. Two sets of timing gates were used, working in opposite directions, to allow participants to start the next run from the end-point of the preceding sprint. A standing start, with the front foot placed $30 \mathrm{~cm}$ behind the timing lights, was used for all sprints. Timing was initiated when the participants broke the light beam. An experimenter was placed at each end of the track to give strong verbal encouragement to each participant at each sprint. Participants were instructed prior to the test to produce maximal effort and to avoid pacing themselves.

The three measures of the RST were ideal sprint time (IS), total sprint time (TS) of the 12 sprints, and performance decrement (PD) during the test. Total sprint time was calculated as the sum of all sprint's times of the test. Ideal sprint time was calculated as the fastest $20 \mathrm{~m}$ sprint run multiplied by 12. Performance decrement was used as an indication of fatigue and was calculated as (total sprint time/ideal sprint time $\times 100)-100$ [15]. The test-retest reliability of the RST is 0.94 for total running time, and 0.75 for performance decrement [15].

Heart rate was measured using a Polar heart rate monitor (Polar Accurex Plus, Polar Electro, Woodbury, NY) at the end of each test (e.g. treadmill, $20 \mathrm{~m}$ shuttle run, WAnT etc.), and immediately after completion of each run during the RST. Rate of perceived exertion (RPE) was determined using the modified (1-10) Borg scale [5] at the end of each test. 


\section{Music protocol}

The music selection for the present study, was based on the hierarchical four factor conceptual model $[9,21,22]$, indicating that strong rhythm and fast tempo (>120 BPM), followed by the musicality, the suitability of music to the athlete's socio-cultural background, and lastly, the extra-musical associations triggered by music, contribute to the music psycho-physical motivational qualities. It was suggested that the rhythm and tempo should match the desired heart rate during the selected physical activity [30], and therefore, we selected a Western CD collection of greatest hits of all times converted to dance style with a tempo of 140-160 BPM (aerobimix spinning, IMP records Ltd., 2004). Four tracks (numbers 3, 5, 8 \&13) with accumulated time of 15 min were selected ("Freed from Desire"- Gala, 1996, "Time after Time"Cyndi Lauper, 1984, "California Dreaming" - The Mamas and the Papas, 1965, and "Heaven" - Bryan Adams, 1983). Since Western music is very popular in our country, this $\mathrm{CD}$ is used frequently in health clubs, schools and sports colleges for aerobic training, and thus also fulfills the criteria of the music's suitability to socio-cultural background and strong association to sport. Music was played by a stereo CD player (Sony CFD-V7). The music volume was equal to 70 decibels. We have previously demonstrated that listening to selected tracks from this $\mathrm{CD}$ (ranked by the participants as a means to increase activity) during warm-up improved peak anaerobic power in elite volleyball players [14].

\section{Statistical analyses}

A two-way repeated measure ANOVA with Bonferroni adjustments was used to compare differences in total treadmill running time, total running distance in the $20 \mathrm{~m}$ shuttle run, peak and mean anaerobic power and fatigue index in the WAnT, and RST's ideal sprint time (IS), total sprint time (TS) and performance decrement (PD), as well as heart rate and RPE in all tests between the exercise with and without motivational music. Data are presented as mean \pm SD. Significance level was set at $\mathrm{p}<0.05$.

\section{RESULTS}

\section{Aerobic tests}

Treadmill running time was significantly longer with, compared to without, background motivational music ( $\mathrm{p}<0.007$, Figure 1 ). There were no significant differences in maximal heart rate $(206.3 \pm 4.3$ versus $203.8 \pm 8.4$ beats/ 
min) during the treadmill run with or without music. RPE was significantly lower during treadmill running with, compared to without, music $(6.1 \pm 1.6$ versus $7.9 \pm 1.1, \mathrm{p}<0.01)$. There was no significant difference in the running distance during the $20 \mathrm{~m}$ shuttle run with or without music (Figure 1). There were no significant differences in maximal heart rate $(198.1 \pm 10.0$ versus $191.6 \pm 13.1$ beats $/ \mathrm{min})$ and RPE $(7.2 \pm 1.6$ versus $7.2 \pm 1.9)$ during the $20 \mathrm{~m}$ shuttle run with or without music.

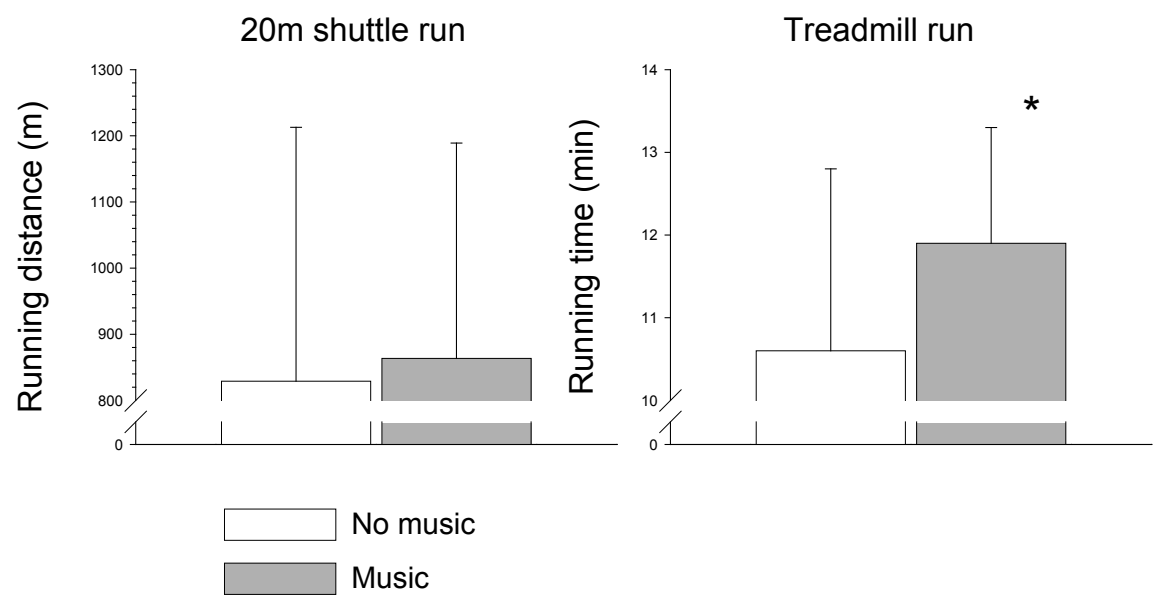

Figure 1. Effect of background motivational music on aerobic performance (20m shuttle run-left panel, treadmill run-right panel).

\section{Anaerobic tests}

There was no significant difference in peak and mean anaerobic power and fatigue index during the WAnT with and without music (Figure 2). There were no significant differences in maximal heart rate (188.4 \pm 7.1 versus $186.8 \pm 6.3$ beats $/ \mathrm{min})$ and RPE $(8.7 \pm 1.3$ versus $8.7 \pm 1.4)$ during the WAnT with or without music.

Total sprint time was significantly faster during the RST with, compared to without, background motivational music $(\mathrm{p}<0.04)$. There were no significant differences in ideal sprint time and performance decrement between RST with and without music (Figure 2). There were no significant differences in maximal heart rate with and without music ( $162.4 \pm 7.5$ versus $162.8 \pm 9.6$ beats $/ \mathrm{min})$. However, RPE was significantly lower during RST with, compared to without, music ( $5.6 \pm 1.3$ versus $7.0 \pm 1.8, \mathrm{p}<0.008)$. 

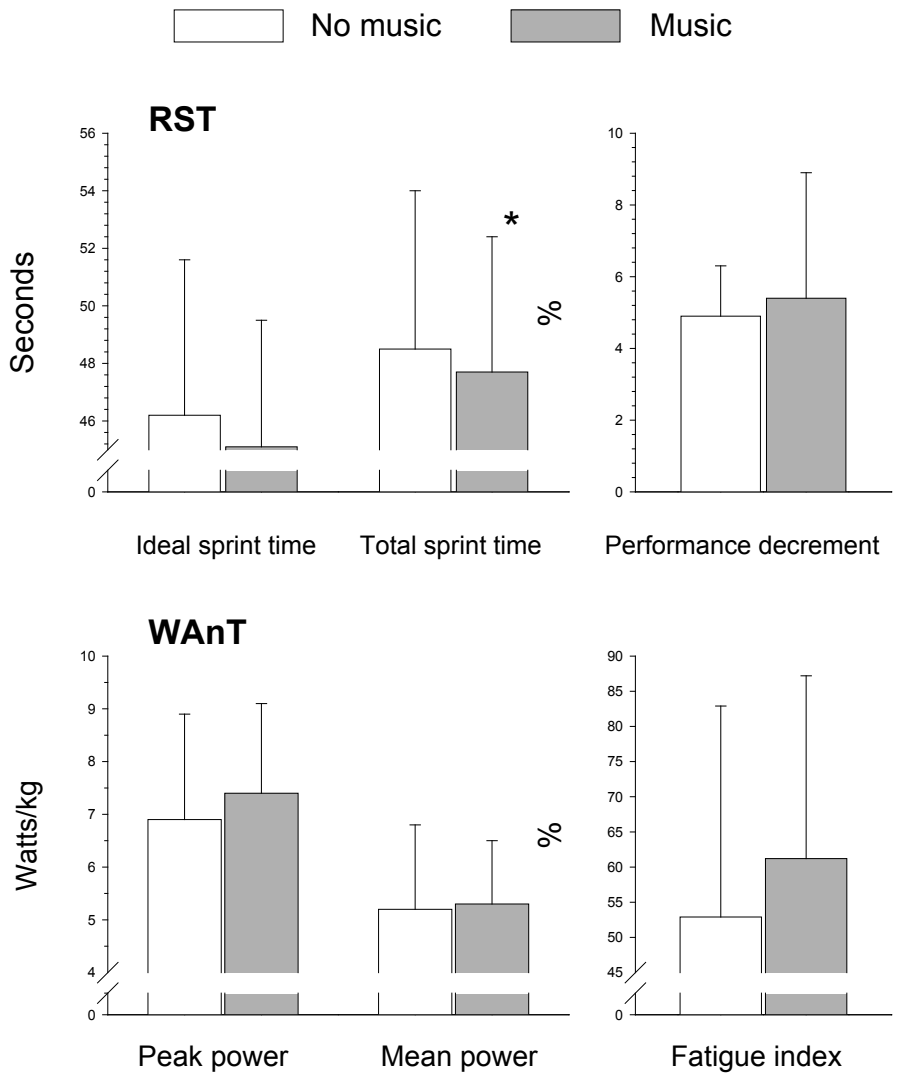

Figure 2. Effect of background motivational music on anaerobic performance (RST-upper panel, WAnT-lower panel).

\section{DISCUSSION}

Childhood obesity has gained epidemic proportions in Westernized societies. The mechanism responsible for the increased prevalence of childhood obesity is not clearly understood, but life-style changes associated with increased caloric intake and decreased energy expenditure probably play a major role. It was suggested that obese children often fail to follow the recommended guidelines of 60 min daily moderated to vigorous physical activity, at least partially, because of their inability to overcome unpleasant exercise-related body symptoms and sensations [2]. Thus, the aim of the present study was to examine the effect of background motivational music on aerobic and anaerobic performance among obese children. Listening to background motivational music was associated with a significant improvement of aerobic capacity in the treadmill run, but not in the $20 \mathrm{~m}$ shuttle run 
(Figure 1). Listening to background motivational music was also associated with a significant improvement of anaerobic capacity determined by total sprint time during the $12 \times 20 \mathrm{~m}$ RST (Figure 2). Along with the improved performance, both the treadmill and RST tests were also associated with a significantly reduced rating of perceived exertion. In contrast, listening to motivational music had no effect on anaerobic capacity determined by indices of the Wingate anaerobic test (WAnT).

Listening to background motivational music was associated with a significantly longer treadmill running time (Figure 1). Moreover, despite the longer running time, exercise was perceived as significantly less intense when background motivational music was played. This is consistent with De Bourdeaudhuij et al [10] who showed that obese children run significantly longer in a treadmill test while listening to their favorite music compared to the same treadmill test without listening to music. The effect of music seemed to be larger at the initial phases of a weight management program for the treatment of childhood obesity. The authors concluded that music distracted obese children from unpleasant body sensations, and postponed the decision to stop the treadmill test, thus leading to improved peak performance. This was based on self-reports of the participants indicating more thoughts about trying to carry on the treadmill test when music was not played.

It was suggested that obese children often fail to carry on physical activity for long time periods [10]. Therefore, the results of the present study and of De Bourdeaudhuij's study [10] suggest that background music (motivational and/or favorite) may be used as a potential way to distract obese children and adolescents from unpleasant feelings that tend to shorten their activity time. It should be mentioned, however, that potential external distracters from body sensations should be used with caution, since these sensations may provide important functional information in order to adapt each individual's exercise duration, pace and intensity.

Surprisingly, motivational music had no significant beneficial effect on aerobic capacity in the $20 \mathrm{~m}$ shuttle run test. We believe that the reason for this discrepancy result from the nature of the $20 \mathrm{~m}$ shuttle run test where a beep sound dictates the running speed. During the test with background music, it was harder for the participants to hear the beep. Thus, participants' attention may have been focused on the beep rather than on the music, not enabling music to distract them from the exercise-associated body feelings, any more.

The results of the present study also showed that music was associated with significantly faster RST total sprint time but had no effect on ideal 
sprint time and performance decrement. In addition, exercise was also perceived as significantly less intense when background motivational music was played. It is possible that only when exercise duration is long enough, background music can have beneficial impact on performance. Therefore, music had no effect on the short IS performance (determined from the fastest sprint: $\sim 4 \mathrm{~s}$ ) and had a significant effect only on the relatively long TS performance ( $48 \mathrm{~s})$. In addition, it is also possible that the music's beneficial effect results, at least partially, from enhancement of the recovery between sprints and not from a positive effect on sprinting performance per se.

Interestingly, music had no significant effects on anaerobic capacity determined by indices of the Wingate anaerobic test. This may be explained by the fact that exercise intensity during the WAnT was greater than exercise intensity during the RST (as indicated by mean heart rate of $188.4 \pm 7.1$ beats/ min and RPE of $8.7 \pm 1.3$ during the WAnT, compared to mean heart rate of $162.4 \pm 7.5$ beats/min and RPE of $5.6 \pm 1.3$ during the RST). It was previously demonstrated that during very intense exercise conditions, music has no beneficial effect on performance $[25,29]$. Several mechanisms may explain the reduced, or lack of impact of music during phases of supra-maximal intensity. Physical exertion results mainly from the exercise intensity and duration. During markedly intense exercise, the athletes experience a scale of exertion feelings, ranging from discrete symptoms to extreme general fatigue, and exhaustion. Listening to music distracts the athlete from the simultaneous exercise-associated sensation of fatigue (the parallel processing model) [26]. It is suggested that this mechanism operates mainly during low to moderate intensity exercise, when external signals can compete with internal signals. During high intensity exercise, internal cues, such as fatigue, have a stronger impact on mental status. Therefore, the effectiveness of external distracter, like music, is limited. In addition, the relatively short exercise duration (i.e. $30 \mathrm{~s}$ ) of the WAnT, and its continuous nature without recovery periods may also explain the lack of beneficial music effects.

Consistent with our findings in untrained relatively unfit overweight children, previous reports have demonstrated that music effects are inversely related to the participant's fitness level, had significantly greater enhancing effects in untrained participants, and were significantly more effective in obese subjects during the initial stages of training/weight reduction programs $[6,10,17]$. Whether the beneficial effect of background motivational music on aerobic and anaerobic capacity in overweight children is reduced after the initial phases of training, or after they lose weight, needs to be further investigated. 
In summary, listening to background motivational music was associated with a significant improvement of both aerobic and anaerobic performance, along with reduced perceived exertion, in overweight children. The results suggest that music may be used as a potential way to distract overweight children and adolescents from unpleasant feeling that tend to shorten activity time. Interestingly, music had no beneficial effect on performance during very intense exercise conditions, or when the attention of the participants was shifted away from music. Further studied are needed to examine the effect of music on other sport types (e.g. resistant training, swimming, ball games etc.), and during different phases of weight management programs in obese children.

\section{REFERENCES}

1. Bar-Or O. (1987) The Wingate anaerobic test. An update on methodology, reliability and validity. Sports Med. 4: 381-394. https://doi.org/10.2165/00007256-198704060-00001

2. Bar-Or O. (1995) Obesity. In: Sports and exercise for children with chronic health conditions. B. Goldberg (Ed.). Champaign IL: Human Kinetics, pp. 335-353.

3. Becker N, Brett S, Chambliss C, Crowers K, Haring P, Marsh C, Montemayor R. (1994) Mellow and frenetic antecedent music during athletic performance of children, adults, and seniors. Percept Mot Skills, 79: 1043-1046.

https://doi.org/10.2466/pms.1994.79.2.1043

4. Bishop DT, Karageorghis CI, Loizou G. (2007) A grounded theory of young tennis players use of music to manipulate emotional state. J Sport Exerc Psychol, 29: 584-607. https://doi.org/10.1123/jsep.29.5.584

5. Borg GA. (1982) Psychophysical bases of perceived exertion. Med Sci Sports Exerc, 14: 377-381. https://doi.org/10.1249/00005768-198205000-00012

6. Brownley KA, McMurray RG, Hackney AC. (1995) Effects of music on physiological and affective responses to graded treadmill exercise in trained and untrained runners. Int J Psychophysiol, 19: 193-201.

https://doi.org/10.1016/0167-8760(95)00007-F

7. Clement K, Ferre P. (2003) Genetics and the pathophysiology of obesity. Pediatr Res 53: 721-725. https://doi.org/10.1203/01.PDR.0000059753.61905.58

8. Crust L. (2008) Perceived importance of components of asynchronous music during circuit training. J Sport Sci, 26: 1547-1555.

https://doi.org/10.1080/02640410802315427

9. Crust L, Clough PJ. (2006) The influence of rhythm and personality in the endurance response to motivational asynchronous music. J Sports Sci, 24: 187-195. https://doi.org/10.1080/02640410500131514 
10. De Bourdeaudhuij I, Crombez G, Deforche B, Vinaimont F, Debode P, Bouckaert J. (2002) Effects of distraction on treadmill running time in severely obese children and adolescents. Int J Obes Relat Metab Disord, 26: 1023-1029. https://doi.org/10.1038/sj.ijo.0802052

11. Dietz WH. (2004) Overweight in childhood and adolescence. N Engl J Med, 350: 855-857. https://doi.org/10.1056/NEJMp048008

12. Edworthy J, Waring H. (2006) The effects of music tempo and loudness level on treadmill exercise. Ergonomics, 15: 1597-1610.

https://doi.org/10.1080/00140130600899104

13. Eliakim A, Kaven G, Berger I, Friedland O, Wolach B, Nemet D. (2002) The effect of a combined intervention on body mass index and fitness in obese children and adolescents - a clinical experience. Eur J Pediatr, 161: 449-454.

https://doi.org/10.1007/s00431-002-0980-2

14. Eliakim M, Meckel Y, Nemet D, Eliakim A. (2007) The effect of music on anaerobic performance in elite adolescent volleyball players. Int J Sports Med, 28: 321-325. https://doi.org/10.1055/s-2006-924360

15. Fitzsimons M, Dawson BT, Ward D, Wilkinson A. (1993) Cycling and running tests of repeated sprint ability. Aust J Sci Med Sport, 25: 82-87.

16. Goran MI, Reynolds KD, Lindquist CH. (1999) Role of physical activity in the prevention of obesity in children. Int J Obes Relat Metab Disord, Suppl 3: S18S33. https://doi.org/10.1038/sj.ijo.0800880

17. Hamburg J, Clair AA. (2003) The effects of a movement with music program on measures of balance and gait speed in healthy older adults. J Music Ther, 40: 212-226. https://doi.org/10.1093/jmt/40.3.212

18. Hancox RJ, Milne BJ, Poulton R. (2004) Association between child and adolescent television viewing and adult health: a longitudinal birth cohort study. Lancet, 364: 257-262. https://doi.org/10.1016/S0140-6736(04)16675-0

19. Jackson SA, Csikszentmihalyi M. (1999) Flow in Sports: The keys to optimal experiences and performances. Champaign IL: Human Kinetics.

20. Karageorghis CI, Terry PC. (1997) The psychophysical effect of music in sport and exercise: a review. J Sport Behav, 20: 54-68.

21. Karageorghis CI, Terry PC, Lane AM. (1999) Development and initial validation of an instrument to assess the motivational qualities of music in exercise and sport: The Brunel Music Rating Inventory. J Sport Sci, 17: 713-724. https://doi.org/10.1080/026404199365579

22. Karageorghis CI, Priest DL, Terry PC, Chatzisarantis NLD, Lane AM. (2006) Redesign and initial validation of an instrument to assess the motivational qualities of music in exercise: the Brunel Music Rating Inventory-2. J Sport Sci, 24: 899-909. https://doi.org/10.1080/02640410500298107

23. Leger LA, Mercier D, Gadoury C, Lambert J. (1988) The multistage $20 \mathrm{~m}$ shuttle run test for aerobic fitness. J Sport Sci, 6: 93-101.

https://doi.org/10.1080/02640418808729800 
24. Oude LH, Baur L, Jansen H, Shrewsbury VA, O’Malley C, Stolk RP, Summerbell CD. (2009) Interventions for testing obesity in children. Cochrane Database of systematic Reviews, 1, Art. No.CDOO1872.

25. Pujol TJ, Langenfeld ME. (1999) Influence of music on Wingate Anaerobic Test performance. Percept Mot Skills, 88: 292-296. https://doi.org/10.2466/pms.1999.88.1.292

26. Rejeski WJ. (1985) Perceived exertion: an active or passive process. J Sport Psychol, 7: 371-378. https://doi.org/10.1123/jsp.7.4.371

27. St Clair Gibson A, Broomhead S, Lambert MI, Hawley JA. (1998) Prediction of maximal oxygen uptake from a $20 \mathrm{~m}$ shuttle run as measured directly in runners and squash players. J Sports Sci, 16: 331-335. https://doi.org/10.1080/02640419808559361

28. Strong WB, Malina RM, Blimkie CJR, Daniels SR, Dishman RK, Gutin B, Hergenroeder AC, Must A, Nixon PA, Pivarnik JM, Rowland T, Trost S, Trudeau F. (2005) Evidence based physical activity for school-age youth. J Pediatr, 146: 732-737. https://doi.org/10.1016/j.jpeds.2005.01.055

29. Tenenbaum G, Lidor R, Lavyan N, Morrow K, Tonnel S, Gershgoren A, Meis J, Johnson M. (2004) The effect of music type on running perseverance and coping with effort sensations. Psychol Sport Exer, 5: 89-109. https://doi.org/10.1016/S1469-0292(02)00041-9

30. Terry PC, Karageorghis CI. (2006) Psychophysical effects of music in sport and exercise: An update on theory, research and application. In Psychology bridging the Tasman: Science, culture and practice - Proceedings of the 2006 Joint Conference of the Australian Psychological Society and the New Zealand Psychological Society. M. Katsikitis (Ed.). Melbourne: VIC: Australian Psychological Society, pp. 415-419.

31. Williams CL, Campanaro LA, Squillace M, Bollella M. (1997) Management of childhood obesity in pediatric practice. Ann N Y Acad Sci, 817: 225-240. https:// doi.org/10.1111/j.1749-6632.1997.tb48209.x

\section{Correspondence to:}

Alon Eliakim MD

Child Health \& Sports Center

Pediatric Department

Meir Medical Ceneter

Sackler School of Medicine

Tel-Aviv University, Israel

Tel: 972-9-7471596, Fax: 972-9-7471303

eliakim.alon@clalit.org.il 